Clinical Studies 


\title{
Detection of Circulating Tumour Cells and Survival of Patients with Non-small Cell Lung Cancer
}

\author{
DIMPLE CHUDASAMA ${ }^{1}$, JAMES BARR $^{1}$, JULIE BEESON ${ }^{1}$, EMMA BEDDOW $^{1}$, NIALL MCGONIGLE ${ }^{1}$, \\ ALEXANDRA RICE ${ }^{2}$, ANDREW NICHOLSON ${ }^{2}$ and VLADIMIR ANIKIN ${ }^{1}$ \\ ${ }^{1}$ Department of Thoracic Surgery, Royal Brompton and Harefield NHS Foundation Trust, London, U.K.; \\ ${ }^{2}$ Department of Histopathology, Royal Brompton and Harefield NHS Foundation Trust, London, U.K.
}

\begin{abstract}
Background: Detection of circulating tumour cells $(C T C s)$ in the peripheral blood of lung cancer patients may predict survival. Various platforms exist that allow capture of these cells for further analysis; little work however, has been done with the ScreenCell device, an antibody-independent CTC platform. The aim of our study was to evaluate the ScreenCell device for detection of CTCs in lung cancer patients and to establish correlations of these findings with survival. Materials and Methods: Twenty-three patients, nine males, and fourteen females, underwent surgical treatment from February to May 2014 for non-small cell lung cancer. Thirteen patients had adenocarcinoma and ten squamous cell carcinoma, while eight were at an early stage (I-II) and five at a later stage (III-IV). Blood samples were obtained prior to surgery and following filtration through the ScreenCell device, were independently reviewed by 2 consultant pathologists. Results: The pathologists were able to independently identify CTCs in $78.3 \%(N=18)$ and $73.9 \%$ $(N=17)$ of the cases examined, with overall $80.6 \%$ in early stages compared to $60.0 \%$ in late stages. The median survival times of positive vs. negative for CTC patients were 1011 and 711 days respectively, with a survival percentage rate of $77.8 \%$ and $60 \%$ in positive and negative CTC cohorts respectively. Conclusion: The results of this study suggest that the presence of CTCs analyzed by ScreenCell did not necessarily lead to a poorer prognosis in patients with lung cancer after curative surgery.
\end{abstract}

This article is freely accessible online.

Correspondence to: Mr. Vladimir Anikin, Consultant Thoracic Surgeon, Department of Thoracic Surgery, Royal Brompton and Harefield NHS Foundation Trust, Hill End Road, Harefield, Middlesex, UB9 6JH, U.K. Tel: +44 1895 828558, e-mail: v.anikin@rbht.nhs.uk

Key Words: ScreenCell, circulating tumour cells, lung cancer.
Mortality from cancer remains high and accounts for $29 \%$ of all deaths (1). The development of metastatic disease is responsible for $90 \%$ of these deaths (2).

Circulating tumour cells (CTCs) are cancer cells of epithelial origin that are present in the peripheral blood samples of cancer patients to form a subpopulation of tumour cells which intravasate to allow lymph haematogenous dissemination in other areas of the body (3).

CTC counts in peripheral blood prior treatment can independently predict the early recurrence in patients with cancer $(3,4)$. Overall survival in patients with stage III and IV non-small cell lung cancer (NSCLC) was significantly longer (8.1 months vs. 4.3 months) in patients with fewer than 5 CTCs compared to those with five or more CTCs before chemotherapy (5). Clusters of CTCs, also known as circulating tumour microemboli (CTM), involve a process of collective cell migration which is important in tumour cell invasion $(6,7)$. CTMs have fewer apoptotic markers than CTCs, and their ability to survive is enhanced. As a result detection of CTMs is associated with a poorer prognosis $(8,9)$. More advanced and/or metastatic cancers express higher levels of CTCs and CTMs (10).

Multiple platforms for CTC isolation exist with varying functionalities. In this study, we used ScreenCell ${ }^{\circledR}$ (Paris, France), which is an antibody-independent device to avoid bias introduced by antibody-dependent techniques such as the CellSearch (Paris, France). The aim of our study was to examine the relationship between the number of CTCs detected by ScreenCell ${ }^{\circledR}$ and survival percentage rate in a NSCLC cohort of patients with surgically resectable lung cancer. Based on our knowledge there are no previous studies that have examined such relationship.

\section{Patients and Methods}

Patients. Twenty-three patients undergoing surgical treatment for suspected or confirmed NSCLC were recruited from February to May 2014. Patients had a confirmed diagnosis of NSCLC either preoperatively or on an intra-operative frozen section. Ethical approval was sought prior (10/H0504/9) and consent was obtained pre- 
operatively. Surgery was performed under the care of four thoracic surgeons at a tertiary thoracic centre. All operations were performed via a thoracotomy beside one, which was done via a video-assisted thoracotomy approach.

The cohort consisted of nine males and fourteen females, with a median age of $66 \pm 11$ years. All patients had primary lung cancer, with a subtype of adenocarcinoma in thirteen $(56.5 \%)$ and squamous cell carcinoma in ten $(43.5 \%)$ patients. Early stage (III) was diagnosed in eighteen and late stage (III-IV) in five patients (Table I). Patients were followed up for a median time period of 31.8 months post-operatively. Survival information and cause of death was obtained by contacting the patient's General Practitioner.

CTC detection using the ScreenCell device. The detailed technique of CTC detection using the ScreenCell device is described elsewhere (11). In brief, three millilitres of blood were collected from the peripheral vein of patients immediately prior to surgery in EDTA-containing tubes. Samples were incubated with $7 \mathrm{ml}$ of a lysis and formaldehyde fixation buffer for $5 \mathrm{~min}$, provided by ScreenCell. Samples were then filtered through the ScreenCell device as per the manufacturer protocol.

Post-filtration filters were removed and stained with Haematoxylin and Eosin (H\&E, Sigma Aldrich, St Louis, MO, USA) staining. Stained filters were then mounted on to slides and viewed by two independent consultant pathologists to assess the presence or not of CTCs. Filters were scored as either positive or negative for atypical cells suspicious for cancer, based on cell morphology and size, typically much larger cells, with nucleus to cytoplasmic ratio larger than normally were deemed as positive (Figure 1).

Statistical analysis was performed using GraphPad Prism v5 (GraphPad, San Diego, CA, USA), survival rate was analysed by Kaplan-Meier curves, statistical significance was calculated using a Chi-square test, and a Hazards Ratio (HR) calculated with a $95 \%$ confidence interval (CI).

\section{Results}

There was no perioperative mortality and all patients were alive at discharge. At follow-up, 17 of the $23(73.9 \%)$ patients were alive and $6(26.1 \%)$ were dead. Two pathologists detected CTCs, one in $18(78.3 \%)$ and the other in $17(73.9 \%)$ of 23 cases. At early-stage cancer patients, CTCs were detected in $80.6 \%(\mathrm{~N}=29)$ of cases compared to $60.0 \%(\mathrm{~N}=6)$ at late-stage patients (Table II).

In the group of six patients $(26.1 \%)$ who tested negative for CTCs, three $(50 \%)$ died during follow-up, two from metastatic lung cancer and one as a result of bowel obstruction. There were three deaths $(18 \%)$ in the group of seventeen patients who tested positive for CTCs, two patients died as a result of lung cancer progression and one patient died as a result of bronchopneumonia.

Out of total six patients that died, four were early-stage III and two were late-stage III-IV. In terms of CTC status in the above patients, there was concordance in five of the cases $(83.3 \%)$ and disagreement in only one case $(16.7 \%)$. The median survival time in patients who died in the CTC-
Table I. Details patient demographics and diagnosis.

\begin{tabular}{lcc}
\hline Variable & Value & Percent $(\%)$ \\
\hline Total patients & 23 & - \\
Mean age $( \pm$ SD) years & $66 \pm 11$ & - \\
Males/Females & $9 / 14$ & $39.1 \% / 60.9 \%$ \\
Pathology & & \\
$\quad$ Primary lung cancer & 23 & $100.0 \%$ \\
$\quad$ Adenocarcinoma & 13 & $56.5 \%$ \\
$\quad$ Squamous Cell Carcinoma & 10 & $43.5 \%$ \\
TNM (Tumour, node, metastasis) staging & & \\
$\quad$ Early stage (IA-IIB) & 18 & $78.3 \%$ \\
Late stage (III-IV) & 5 & $21.7 \%$ \\
\hline
\end{tabular}

negative and in the CTC-positive group was 650 days and 836 days, respectively. Median follow-up time of the survivors was 1,008 days (Table III).

The Kaplan-Meier survival curves, showed a poorer survival proportion in the CTC negative group compared to the CTC positive group, with a chi-square value of 11.08 , shown as being statistically significant $(p<0.0009)$ and a HR of 0.04453 (95\% CI; range, 0.007131 to 0.2781 ) (Figure 2).

\section{Discussion}

Detection of CTCs can be difficult as only one CTC may be found in a background of $1 \times 10^{5}$ to $1 \times 10^{6}$ peripheral blood mononuclear cells (12). Another challenge lies in the biological characteristics of CTCs that can differ from those of the primary tumour. CTCs acquire genetic mutations equipping them to respond to local growth factors and stimulate neovascularisation. Several studies in breast cancer patients have found that HER2 expression differed between CTCs and the primary tumour. It has thus been postulated that CTCs expressing different biomarkers from the primary tumour may respond differently to treatments (13-16).

Several studies have compared the performance of different technologies to find varying results, in particular between antibody-dependent and antibody-independent devices. It is becoming increasingly evident that some epithelial properties are lost from cancer cells, in some cancers more than others $(17,18)$. Hence, epithelial expression-based methods such as the CellSearch device, may have a disadvantage (despite being the only FDA approved CTC isolation device) over expressionindependant, filtration-type platforms such as ISET (RareCells, Paris, France) or ScreenCell which rely on cell size and other physical cellular properties. There are a multitude devices available on the market, with varying functionality (19-25). 

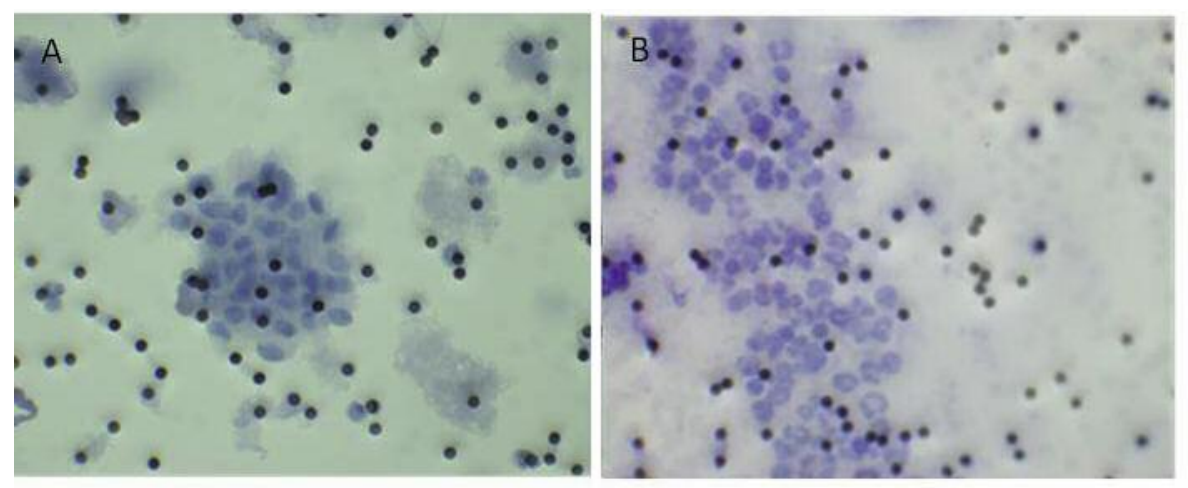

Figure 1. Representative results of a positive slide of captured suspicious cancer cells on ScreenCell filter and a negative slide (haemotoxylin and eosin staining). (A) A large cluster of atypical cancer cells (40x magnification). Individual cell features can be seen, such as large irregular nucleus and small cytoplasmic layer. Overall size of cells is much larger ( $>8 \mu \mathrm{m}$, comparable to circular pores on the filter), compared to normal blood cells seen in the surrounding. (B) Negative slide showing contaminating leukocytes (40x magnification).

\section{Survival of Data 1:Survival proportions}

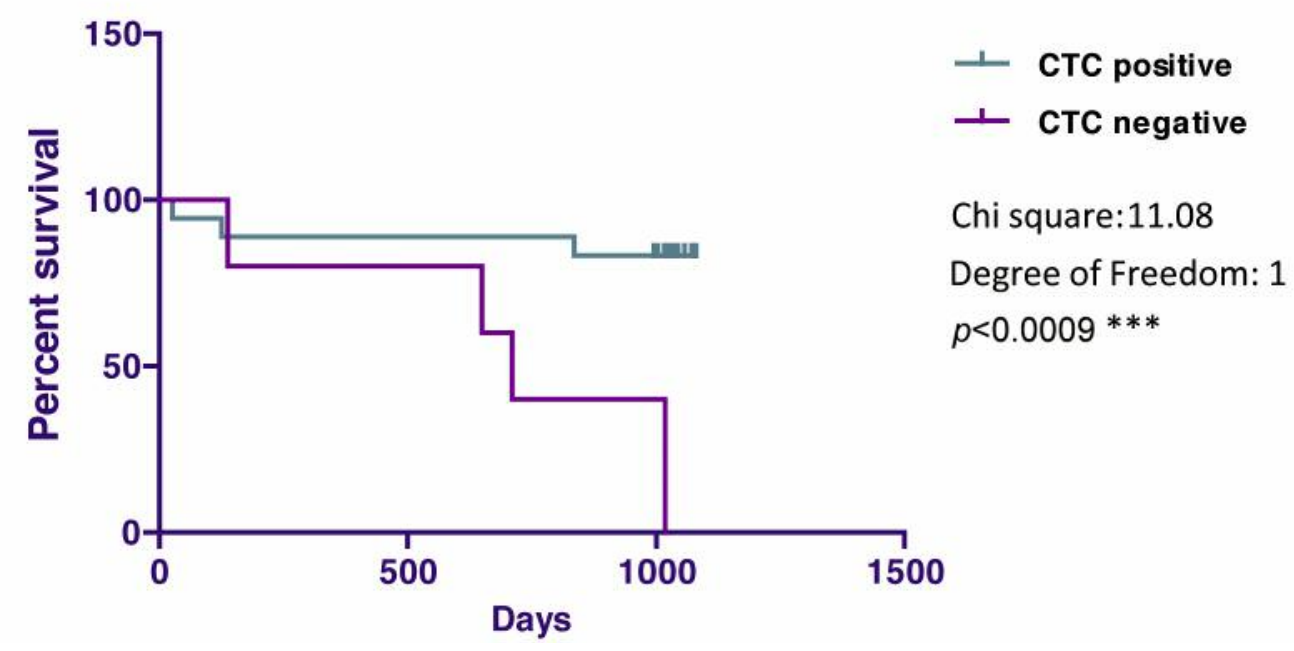

Figure 2. Kaplan-Meier plot of survival, showing higher survival proportion to patients in the CTC negative group compared to those in the CTC positive group. A chi-square value of 11.08 was calculated as statistically significant with a p-value $<0.0009$ and HR of 0.04453 (95\% CI; range, 0.007131 to 0.2781 ).

Table II. Results of ScreenCell filter viewing by 2 independent pathologists.

\begin{tabular}{lccc}
\hline Group & Pathologist A & Pathologist B & Overall Average \\
\hline Cancer samples & $18 / 23(78.3 \%)$ & $17 / 23(73.9 \%)$ & $35 / 46(76.1 \%))$ \\
Early stage cancer (I-II) & $15 / 18(83.3 \%)$ & $14 / 18(78.0 \%)$ & $29 / 36(80.6 \%)$ \\
Advanced stage cancer (III-IV) & $3 / 5(60.0 \%)$ & $3 / 5(60.0 \%)$ & $6 / 10(60.0 \%)$ \\
\hline
\end{tabular}

The CTC detection rate by ScreenCell in our study, was higher compared to similar studies looking at patients with early-stage NSCLC. Freidin et al. (2014) reported CTC detection rates of $56 \%$ and $65 \%$ by two separate pathologists using ScreenCell in patients undergoing surgery for early-stage lung cancer in comparison to $78.3 \%(\mathrm{~N}=15)$ and $73.9 \%(\mathrm{~N}=14)$ detection rates in our study (Table II) (26). This could partly be explained by the subjective nature of the method of identification, particularly in the absence of any special or specific antibody stains. However, our 
Table III. Patient follow-up and survival data based on CTC presence or absence.

\begin{tabular}{lcc}
\hline & CTC positive & CTC negative \\
\hline Number of patients & 18 & 5 \\
Alive at follow up & 14 & 3 \\
Median survival (days) & 1011 & 711 \\
\hline
\end{tabular}

detection rates were similar in comparison to studies looking at patients with more advanced NSCLC with $60 \%$ for both Pathologists, although it must be noted the advanced cancer sample numbers comprised a very small proportion of the cohort, Mascalchi et al. (2015) reported detection rates of CTCs using ScreenCell of $65 \%$ in a cohort of 26 patients with stage III and IV NSCLC. The authors found no correlation between tumour stage and the number of CTCs detected (27). Our detection rates, in comparison to other studies, support the idea that the release of CTCs is not related to tumour stage. A study by Wendel et al. (2012) found no significant differences in the median number of CTCs in patients with different stages of NSCLC detected by using a fluid phase biopsy approach (28). However, there is contradictory evidence since Krebs et al. (2011) found that the number of CTCs correlated with NSCLC stage. Patients at a higher NSCLC stage, had a greater number of CTCs. CTCs were detected using a semi-automated, epithelial cell adhesion molecule-based immunomagnetic technique (5). The conflicting evidence may be due to the different methods of CTC detection and that CTCs detected by different methods may have different biological characteristics.

In our study, patients negative for CTCs had a higher mortality rate during the study period, with $40 \%(\mathrm{~N}=2)$ in patients negative or CTCs $v s .22 .2 \%(\mathrm{~N}=4) \%$ in patients positive for CTCs (Table III). Additionally, in patients who died the median survival was shorter in those who were positive for CTCs. These results differ from other studies where patients who tested positive for CTCs had a worse prognosis. Krebs et al. (2011) found that prognosis was significantly worse in patients with stage III and IV NSCLC who had more circulating tumour cells (5).

These differences in survival may reflect the way that CTCs are analyzed. ScreenCell detects CTCs based on size exclusion, not allowing larger epithelial cells to pass through the micropores of the filtration device. On the other hand, Krebs et al. (2011) used an antigen-based technique. It may be that although ScreenCell is detecting CTCs it may not detecting clinically relevant CTCs that have the biological properties to influence the survival of NSCLC by establishing metastatic disease. Additionally there may be differences in the characteristics of CTCs in early-stage lung cancer and more advanced NSCLC (5). An alternative hypothesis that could explain the lower mortality rate would be that CTC detection in early-stage NSCLC could prime the immune system to respond more effectively against CTCs.

Our results indicate that detection of CTCs using ScreenCell is not necessarily prognostic and the detection of CTCs should not preclude the patient from undergoing surgical resection. The limitations of our study is the small cohort size, as well as analysing retrospective data. Additionally, our analysis was performed based on whether the patient had CTCs or not rather than looking at the effect of the total number of CTCs on prognosis.

In conclusion, our results do not support the idea that detection of CTCs using ScreenCell equates to a worse prognosis in comparison to patients who tested positive for CTCs using ScreenCell. Detection of CTCs by ScreenCell should not prevent patients from undergoing surgery with curative intent. More research is needed into this field to investigate the application of ScreenCell in other forms of cancers and in particularly to check whether in more advanced cancers this technology does show a correlation between CTC detection and poor prognosis. Additionally, it would be useful to look in the future at the different biological characteristics of CTCs detected by different methods.

\section{References}

1 Cancer Res UK, 2016.

2 Delloye-Bourgeois C, Fitamant J, Paradisi A, Cappellen D, DoucRasy S, Raquin M-A, Stupack D, Nakagawara A, Rousseau R, Combaret V, Puisieux A, Valteau-Couanet D, Bénard J, Bernet A and Mehlen P: Netrin-1 acts as a survival factor for aggressive neuroblastoma. J Exp Med 206: 833-847, 2009.

3 Fidler IJ: The pathogenesis of cancer metastasis: the "seed and soil” hypothesis revisited. Nat Rev Cancer 3: 453-458, 2003.

4 Hou J-M, Krebs M, Ward T, Morris K, Sloane R, Blackhall F and Dive C: Circulating tumor cells, enumeration and beyond. Cancers (Basel) 2: 1236-1250, 2010.

5 Krebs MG, Sloane R, Priest L, Lancashire L, Hou J-M, Greystoke A, Ward TH, Ferraldeschi R, Hughes A, Clack G, Ranson M, Dive C and Blackhall FH: Evaluation and prognostic significance of circulating tumor cells in patients with nonsmall-cell lung cancer. J Clin Oncol 29: 1556-1563, 2011.

6 Friedl $\mathrm{P}$ and Wolf K: Tumour-cell invasion and migration: diversity and escape mechanisms. Nat Rev Cancer 3: 362-374, 2003.

7 Ilina $\mathrm{O}$ and Friedl P: Mechanisms of collective cell migration at a glance. J Cell Sci 122: 3203-3208, 2009.

8 Carter L, Metcalf R, Blackhall FH, Dive C and Krebs MG: Biology and clinical relevance of circulating tumour cells. J Thorac Dis 4: 453-455, 2012.

9 Cho EH: Circulating tumor cells as emerging tumor biomarkers in lung cancer. J Thorac Dis 4: 444-445, 2012.

10 Paterlini-Brechot $\mathrm{P}$ and Benali NL: Circulating tumor cells (CTC) detection: clinical impact and future directions. Cancer Lett 253: 180-204, 2007. 
11 Chudasama D, Rice A, Anikin V, Soppa G and Dalal P: Circulating Tumour Cells in Patients with Malignant Lung Tumors Undergoing Radio-frequency Ablation. Anticancer Res 35: 2823-2826, 2015

12 Hou HW, Warkiani ME, Khoo BL, Li ZR, Soo RA, Tan DS-W, Lim W-T, Han J, Bhagat AAS and Lim CT: Isolation and retrieval of circulating tumor cells using centrifugal forces. Sci Rep 3: 1259, 2013.

13 Riethdorf S, Fritsche H, Müller V, Rau T, Schindlbeck C, Rack B, Janni W, Coith C, Beck K, Jänicke F, Jackson S, Gornet T, Cristofanilli $\mathrm{M}$ and Pantel $\mathrm{K}$ : Detection of circulating tumor cells in peripheral blood of patients with metastatic breast cancer: a validation study of the CellSearch system. Clin Cancer Res 13: 920-928, 2007.

14 Nadal R, Fernandez A, Sanchez-Rovira P, Salido M, Rodríguez $\mathrm{M}$, García-Puche JL, Macià $\mathrm{M}$, Corominas JM, DelgadoRodriguez M, Gonzalez L, Albanell J, Fernández M, Solé F, Lorente JA and Serrano MJ: Biomarkers characterization of circulating tumour cells in breast cancer patients. Breast Cancer Res 14: R71, 2012.

15 Solomayer EF, Becker S, Pergola-Becker G, Bachmann R, Krämer B, Vogel U, Neubauer H, Wallwiener D, Huober J and Fehm TN: Comparison of HER2 status between primary tumor and disseminated tumor cells in primary breast cancer patients Breast Cancer Res Treat 98: 179-184, 2006.

16 Munzone E, Nolé F, Goldhirsch A, Botteri E, Esposito A, Zorzino L, Curigliano G, Minchella I, Adamoli L, Cassatella MC, Casadio C and Sandri MT: Changes of HER2 status in circulating tumor cells compared with the primary tumor during treatment for advanced breast cancer. Clin Breast Cancer 10: 392-397, 2010.

17 Hiltermann TJN, van der Wekken AJ and Groen HJM: Moving forward with circulating tumor cells and lung cancer. J Thorac Dis 4: 440-441, 2012.

18 Hou J-M, Krebs M, Ward T, Sloane R, Priest L, Hughes A, Clack G, Ranson M, Blackhall F and Dive C: Circulating tumor cells as a window on metastasis biology in lung cancer. Am J Pathol 178: 989-996, 2011.

19 Allard WJ, Matera J, Miller MC, Repollet M, Connelly MC, Rao C, Tibbe AGJ, Uhr JW and Terstappen LWMM: Tumor cells circulate in the peripheral blood of all major carcinomas but not in healthy subjects or patients with nonmalignant diseases. Clin Cancer Res 10: 6897-6904, 2004.

20 Tewes M, Aktas B, Welt A, Mueller S, Hauch S, Kimmig R and Kasimir-Bauer S: Molecular profiling and predictive value of circulating tumor cells in patients with metastatic breast cancer: an option for monitoring response to breast cancer related therapies. Breast Cancer Res Treat 115: 581-590, 2009.
21 Vona G, Sabile A, Louha M, Sitruk V, Romana S, Schütze K, Capron F, Franco D, Pazzagli M, Vekemans M, Lacour B, Bréchot $\mathrm{C}$ and Paterlini-Bréchot $\mathrm{P}$ : Isolation by size of epithelial tumor cells: a new method for the immunomorphological and molecular characterization of circulatingtumor cells. Am J Pathol 156: 57-63, 2000.

22 Desitter I, Guerrouahen BS, Benali-Furet N, Wechsler J, Jänne PA, Kuang Y, Yanagita M, Wang L, Berkowitz JA, Distel RJ and Cayre YE: A new device for rapid isolation by size and characterization of rare circulating tumor cells. Anticancer Res 31: 427-441, 2011.

23 Hoshimoto S, Shingai T, Morton DL, Kuo C, Faries MB, Chong $\mathrm{K}$, Elashoff D, Wang H-J, Elashoff RM and Hoon DSB: Association between circulating tumor cells and prognosis in patients with stage III melanoma with sentinel lymph node metastasis in a phase III international multicenter trial. J Clin Oncol 30: 3819-3926, 2012.

24 Gertler R, Rosenberg R, Fuehrer K, Dahm M, Nekarda H and Siewert JR: Detection of circulating tumor cells in blood using an optimized density gradient centrifugation. Recent results cancer Res Fortschritte der Krebsforsch Progrès dans les Rech sur le cancer 162: 149-155, 2003.

25 McNiece I, Briddell R, Stoney G, Kern B, Zilm K, Recktenwald $\mathrm{D}$ and Miltenyi S: Large-scale isolation of CD34+ cells using the Amgen cell selection device results in high levels of purity and recovery. J Hematother 6: 5-11, 1997.

26 Freidin MB, Tay A, Freydina D V, Chudasama D, Nicholson AG, Rice A, Anikin V and Lim E: An assessment of diagnostic performance of a filter-based antibody-independent peripheral blood circulating tumour cell capture paired with cytomorphologic criteria for the diagnosis of cancer. Lung Cancer 85: 182-185, 2014.

27 Mascalchi M, Falchini M, Maddau C, Salvianti F, Nistri M, Bertelli E, Sali L, Zuccherelli S, Vella A, Matucci M, Voltolini L, Pegna AL, Luconi M, Pinzani P and Pazzagli M: Prevalence and number of circulating tumour cells and microemboli at diagnosis of advanced NSCLC. J Cancer Res Clin Oncol, 2015.

28 Wendel M, Bazhenova L, Boshuizen R, Kolatkar A, Honnatti M, Cho EH, Marrinucci D, Sandhu A, Perricone A, Thistlethwaite P, Bethel K, Nieva J, Heuvel M van den and Kuhn P: Fluid biopsy for circulating tumor cell identification in patients with early-and late-stage non-small cell lung cancer: a glimpse into lung cancer biology. Phys Biol 9: 016005, 2012.

Received October 14, 2016

Revised November 8, 2016

Accepted November 22, 2016 